\title{
ADESÃO À ORGANIZAÇÃO PARA A COOPERAÇÃO E DESENVOLVIMENTO ECONÔMICO, EXPORTAÇÕES E INVESTIMENTOS: UMA ANÁLISE EXPLORATÓRIA
}

José Guilherme Reis ${ }^{1}$

André Soares²

Desde 2017, o governo brasileiro estabeleceu como objetivo a adesão à Organização para a Cooperação e Desenvolvimento Econômico (OCDE), uma instituição formada por 36 países membros que buscam discutir, difundir e alinhar melhores práticas em termos de governança e políticas públicas. A OCDE tem se expandido em anos recentes, tendo incluído dez países desde a década de 1990. É natural que haja interesse em conhecer os possíveis impactos dessa adesão sobre o desempenho econômico dos países. A literatura recente sobre cadeias globais de valor (CGVs) sugere que aspectos extratarifários que têm sido crescentemente incorporados a acordos comerciais tem beneficiado o crescimento dessas cadeias de valor. Neste artigo, utilizando técnicas econométricas diversas, fazemos uma análise exploratória do desempenho das exportações e dos investimentos estrangeiros diretos desses países, em comparação com o desempenho dos países que não aderiram à instituição. Encontramos efeitos significativos, ainda que modestos, sobre ambas as variáveis. Tendo em vista o grau de agregação, preferimos interpretar esses resultados como correlação, e não causalidade. De todo modo, o impacto limitado sugere que ganhos mais substanciais em termos de crescimento e exportações para uma economia como a brasileira requerem medidas de aprofundamento da integração em diversas dimensões, em particular na área de bens e serviços.

Palavras-chave: OCDE; investimentos estrangeiros diretos; comércio; cadeias de valor global.

\section{ACCESSION TO THE ORGANISATION FOR ECONOMIC COOPERATION AND DEVELOPMENT, EXPORTS AND INVESTMENTS: AN EXPLORATORY ANALYSIS}

The Brazilian government has set, in 2017, the goal of joining Organisation for Economic Cooperation and Development (OECD), an institution formed by 36 member countries that seek to discuss, disseminate, and align best practices in terms of public policies and governance. The OECD has expanded in recent years, including ten countries since the 1990s. The prospects of Brazil joining the OECD have sparked an interest from policy makers and even the public to know the possible economic impacts of becoming a member country. For example, recent literature on global value chains suggests that non-tariff related measures, such as the one practiced by OECD members, have been increasingly incorporated into trade agreements and have benefited the growth of these value chains. In this article, using different econometric techniques, we make an exploratory analysis of the performance of exports and foreign direct investments of countries that joined the OECD after the 1990s. We also compared their trade and FDI performance with the performance of countries that have not joined the organization. We found significant, albeit modest, effects on both variables. Considering the level of aggregation of the available data for

1. Diretor Executivo por Brasil e Suriname no Banco Interamericano de Desenvolvimento. E-mail: <joseal@iadb.org>. Orcid: <https://orcid.org/0000-0003-3418-0129>.

2. Conselheiro por Brasil e Suriname no Banco Interamericano de Desenvolvimento. E-mail: <andreluizs@iadb.org>. Orcid: <https://orcid.org/0000-0001-8025-9618>. 
this analysis, we prefer to interpret these results as correlation, not causality. In any case, the limited impact suggests that more substantial gains in terms of FDI and exports growth to Brazil would require the adoption of measures to deepen the integration of the Brazilian economy to global value chains in several dimensions, particularly in goods and services.

Keywords: OECD; foreign direct investments; trade; global value chains.

\section{ADHESIÓN A LA ORGANIZACIÓN PARA LA COOPERACIÓN Y EL DESARROLLO ECONÓMICOS, EXPORTACIONES E INVERSIONES: UN ANÁLISIS EXPLORATORIO}

Desde 2017, el gobierno brasileño se ha propuesto ingresar en la Organización para la Cooperación y el Desarrollo Económicos (OCDE), una institución formada por 36 países miembros que busca discutir, difundir y alinear las mejores prácticas en materia de gobernanza y políticas públicas. La OCDE se ha ampliado en los últimos años para incluir a diez países desde la década de 1990. Es natural que haya interés por conocer las posibles repercusiones de esta adhesión en los resultados económicos de los países. La literatura reciente sobre las cadenas globales de valor sugiere que los aspectos extra-arancelarios que se han incorporado a los acuerdos comerciales han beneficiado el crecimiento de estas cadenas de valor. En este artículo, utilizando varias técnicas econométricas, hacemos un análisis exploratorio de los resultados de las exportaciones y de las inversiones extranjeras directas de estos países, en comparación con los resultados de los países que no se han adherido. Encontramos efectos significativos, aunque modestos, en ambas variables. Teniendo en cuenta el grado de agregación, preferimos interpretar estos resultados como correlación y no como causalidad. En cualquier caso, el impacto limitado sugiere que los beneficios sustanciales en términos de crecimiento y exportaciones para una economía como la brasileña requieren medidas para profundizar la integración de la economía brasileña en varias dimensiones, particularmente en el área de bienes y servicios.

Palabras clave: OCDE; inversiones extranjeras directas; comercio; cadenas globales de valor.

JEL: F10.

DOI: http://dx.doi.org/10.38116/rtm25art3

Data de envio do artigo: 18/11/2020. Data de aceite: 23/12/2020.

\section{INTRODUÇÃO}

O ingresso do Brasil na Organização para a Cooperação e Desenvolvimento Econômico (OCDE) tem sido um objetivo de política do governo brasileiro desde 2017. Criada em 1961, a OCDE consiste em uma instituiçáo formada por 36 países que buscam discutir, difundir e alinhar melhores práticas em termos de governança e políticas públicas. A OCDE é formada, em grande maioria, por países desenvolvidos, como Estados Unidos, países da Europa Ocidental, Japão e Coréia, mas conta crescentemente com países em desenvolvimento, muitos da Europa Central e Leste Europeu e, mais recentemente, da América Latina, como México, Chile e Colômbia. 
Apesar de o grupo possuir elevado grau de heterogeneidade em termos de tamanho e grau de desenvolvimento de economia, o ingresso de um país na OCDE é visto como sinônimo de sucesso e alcance de patamar mais elevado nos padrôes adotados em suas políticas públicas.

A história do Brasil com a OCDE é composta por diferentes capítulos. No passado, o país foi convidado a ingressar no grupo, porém optou por não seguir em frente com o processo de acessão. Com a mudança política ocorrida a partir de 2016, o Brasil mudou de posição e adotou uma postura proativa de buscar o ingresso na organização.

$\mathrm{O}$ fato de não participar formalmente na $\mathrm{OCDE}$, entretanto, nunca impediu que o Brasil buscasse cooperar e mesmo adotar práticas de políticas públicas sugeridas pela organização. Por exemplo, o próprio site da OCDE indica que o Brasil é o maior parceiro estratégico do grupo, já participando de alguns de seus comitês. As palavras do embaixador Márcio Cozendey, que lidera o processo de adesão do país ao grupo, deixam claro que o Brasil não é estranho a organização e nem as suas práticas: "O Brasil coopera com a OCDE desde os anos 1990. A OCDE tem 253 instrumentos jurídicos, que são recomendações e decisóes, e o Brasil já aderiu a 80 desses instrumentos, o que é 30\% deles". ${ }^{3}$

Dessa forma, o acesso a OCDE tem sido um objetivo de muitos países em desenvolvimento, mormente após o início do processo de enlargement (ampliação) adotado pela organização a partir do fim dos anos 1980. A participação na OCDE funciona como um selo de qualidade para as políticas adotadas por seus países e membros. Como explica Mello (2020, tradução nossa):

nesse sentido, a OCDE tem frequentemente desempenhado o papel de fórum informal e exclusivo de pré-negociaçáo entre os países desenvolvidos, de normas e padróes só posteriormente submetidos a processos de negociação mais institucionalizados e universais em outras instituiçóes. Embora nem sempre tenha sido o próprio lócus da universalizaçáo das normas pactuadas por seus membros, tem desempenhado papel fundamental na seleção dos temas que deveriam fazer parte da agenda da governança internacional, bem como na definiçáo do conteúdo específico de regras a serem adotadas na perspectiva de um país desenvolvido (Mello, 2020, tradução nossa). ${ }^{4}$

Este artigo tem como objetivo explorar, por meio de análise econométrica, regularidades empíricas associadas à obtenção e posse desse "selo de qualidade".

3. Entrevista concedida a BBC Brasil. Disponível em: <https://www.bbc.com/portuguese/brasil-51121488>.

4. "In that sense, the OECD has frequently played the role of an informal and exclusive pre-negotiation forum among developed countries, of norms and patterns only subsequently submitted to more institutionalized and universal negotiating processes in other institutions. Although it has not always been the locus itself of the universalization of the norms agreed upon by its members, it has played a crucial role in selecting the issues that should become part of the international governance agenda, as well as defining the specific content of the rules to be adopted from the perspective of a developed country". 
A hipótese é que a adesão a OECD teria características semelhantes à dimensão não comercial de assinar um acordo comercial profundo. Esse tipo de acordo, cada vez mais frequente, vai muito além da negociação de acesso a mercados; envolve compromissos em áreas como competição, legislação trabalhista, propriedade intelectual e outros.

$\mathrm{O}$ foco do artigo recai sobre indicadores como investimento estrangeiro direto (IED) e comércio exterior (exportaçôes e importaçôes), mais claramente associados à adesão à OCDE. Para tanto, comparamos o desempenho de países que aderiram mais recentemente à organização com o de países que não aderiram, usando diversas técnicas econométricas (ver a seção sobre metodologia e base de dados). Examinamos também uma possível associação com indicadores de governança, como: estabilidade política, regra da lei, qualidade regulatória, efetividade do governo e controle de corrupção.

Após esta introdução, o artigo se estrutura da seguinte forma: primeiro, apresentamos uma análise descritiva sobre as variáveis de comércio e investimento. O objetivo é apresentar as principais características do perfil de comércio e de ingresso de IED em países membros e não membros da OCDE. Em seguida, apresentamos os resultados da parte empírica, buscando avaliar e mensurar o impacto do ingresso na OCDE nos indicadores mencionados. $\mathrm{O}$ artigo conclui com uma breve discussão sobre os resultados encontrados e sugestóes acerca de como o Brasil deve seguir navegando sob o processo de ingresso na organização.

\section{ANÁLISE DESCRITIVA DO PERFIL COMERCIAL DE PAÍSES MEMBROS E NÃO MEMBROS DA OCDE}

Antes de ingressar em uma análise mais profunda sobre o impacto comercial em países que se tornaram membros da OCDE, seria importante analisar em detalhes o perfil comercial dos países que fazem parte do grupo e como isso se compara com aqueles que não fazem parte.

Primeiramente, deve-se ressaltar que é possível observar uma queda da participação no comércio mundial de países membros da OCDE (gráfico 1). No final da década de 1990, eles representavam, em conjunto, quase $90 \%$ do comércio mundial. Hoje, esse número está em $49 \%$. O mesmo pode ser visto no ritmo de crescimento do comércio internacional. Apesar da redução observada no ritmo de crescimento do comércio mundial na última década, os países membros da OCDE possuíram performance inferior à dos náo membros. A média do crescimento comercial das últimas duas décadas deixa claro que o processo de globalização e de expansão das cadeias de suprimento pelo mundo favoreceu países não membros da OCDE. 
GRÁFICO 1

OCDE: perfil comercial de países membros e não membros

(Em \%)

1 A - Participação no comércio internacional

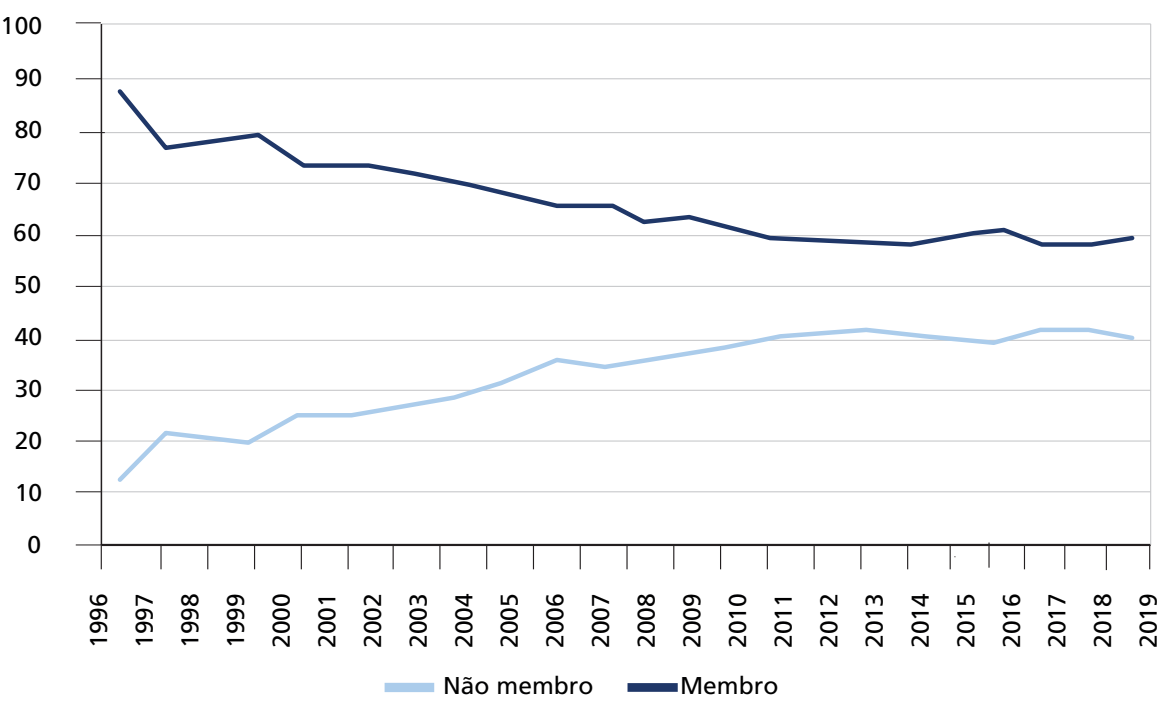

1B - Média do crescimento do comércio

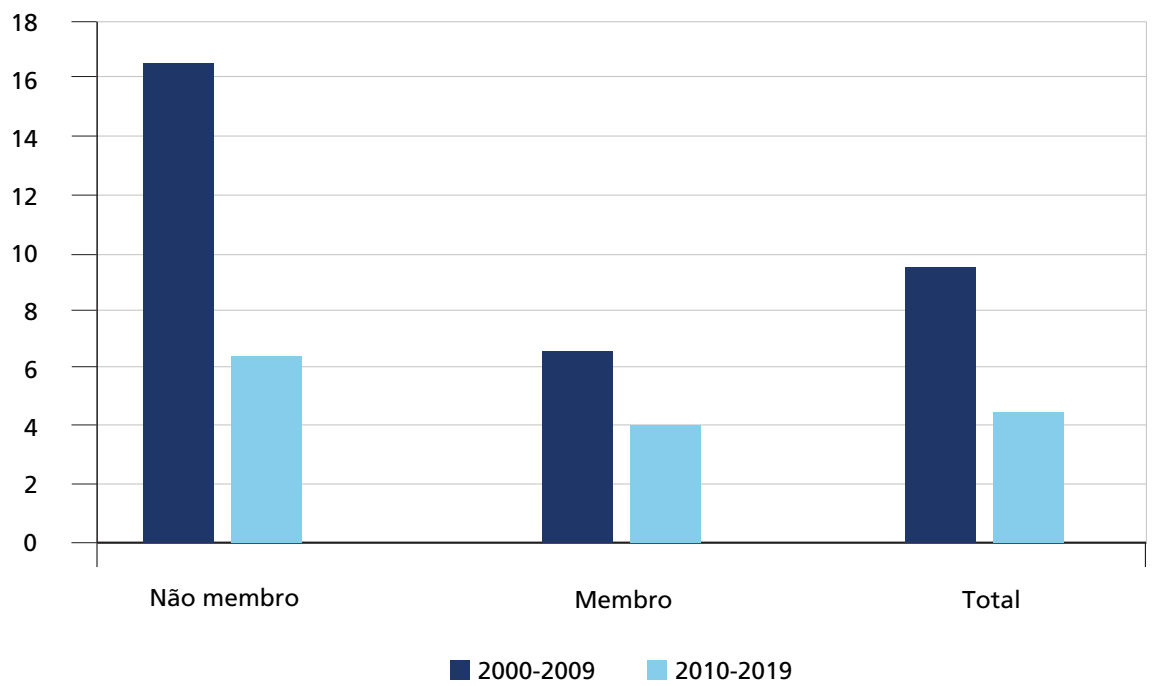

Fonte: Banco de Dados das Estatísticas do Comércio Internacional das Nações Unidas (United Nations International Trade Statistics Database - Comtrade).

Em termos do perfil de exportação (gráfico 2), é nítido que, ao longo das últimas décadas, se observa um grande avanço dos países não membros da OCDE em áreas como bens de capital e bens intermediários. Isso parece reforçar 
a evidência de que a globalização tem movido as cadeias de suprimento de países de economias mais desenvolvidas para outros em desenvolvimento, que passam a se integrar às cadeias globais ou regionais de produção.

É importante notar, entretanto, que os países membros da OCDE ainda possuem liderança na área de bens de consumo. Isso significa que a maior agregação de valor e, por consequência, de retorno em relação ao valor das exportaçóes ainda se mantém em países membros da OCDE. Na área de bens de consumo, observa-se que os países membros perderam apenas 2 pontos percentuais (p.p.) de participação nas exportaçóes globais na última década.

Do mesmo modo, é nítida a liderança de países não membros em relação à exportação de matérias primas. Apesar da OCDE ter membros que são grandes exportadores de produtos naturais, como Austrália e Chile, a maioria dos exportadores de matérias primas se encontra fora do grupo.

Neste momento, vale uma reflexão para a análise empírica que será apresentada mais à frente. Parece existir um viés seletivo de países membros da OCDE em favor daqueles que já possuem características, em termos de vantagens comparativas em fatores de produção, que propiciam a exportação de produtos de maior nível de processamento dentro de uma cadeia de produção. Isso poderia levar ao equívoco de, precocemente, se avaliar que ingressar na OCDE implicaria em maiores exportaçôes de produtos manufaturados.

\section{GRÁFICO 2}

\section{OCDE: exportações por etapa de processamento}

(Em \%)
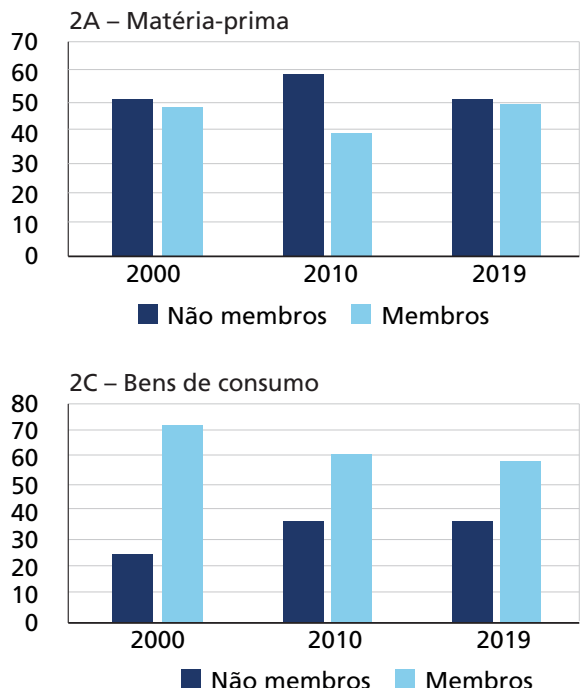

Fonte: Comtrade.
2B - Bens intermediários

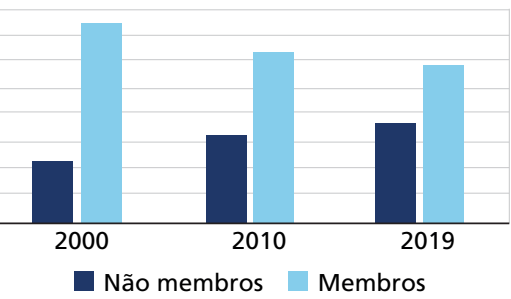

2D - Bens de capital
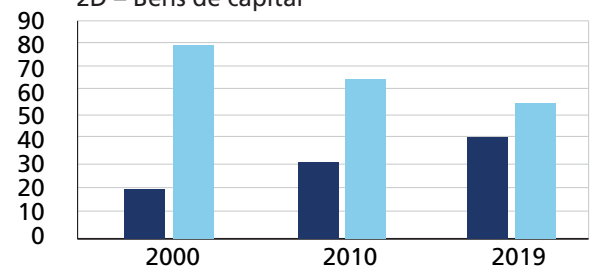

Não membros Membros 
Se, por um lado, esses gráficos indicam que não fazer parte da OCDE não implicaria estar à margem do processo das cadeias globais de suprimento, por outro, deve-se considerar que os ganhos marginais em termos de perfil de exportação podem ser explicados pela ascensão da China, que nas últimas duas décadas emergiu como grande motor de exportação de manufaturados no mundo.

O gráfico 3 deixa claro que, ao retirar a China de cena, a proporção de matérias-primas na pauta de exportação dos países não membros sobre de $13 \%$ para $19 \%$, considerando dados de 2019 . Já a proporção de bens de consumo, cai de $31 \%$ para $28 \%$.

\section{GRÁFICO 3}

OCDE: pauta de exportação por tipo de produto (2019) (Em \%)

3A - Membro

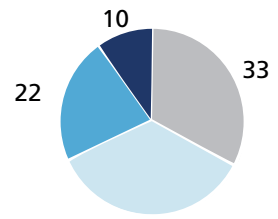

35
3B - Não membro

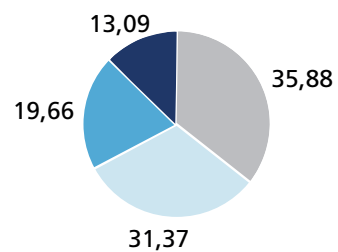

31,37
Bens de capital Bens intermediários Bens de consumo Matéria-prima

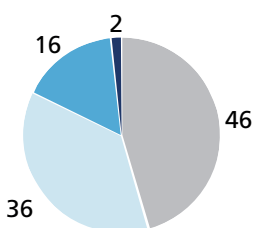

Bens de capital Bens de consumo
Bens intermediários Matéria-prima
Bens de capital Bens de consumo
Bens intermediários Matéria-prima

$$
\text { 3D - Não membro (sem China) }
$$

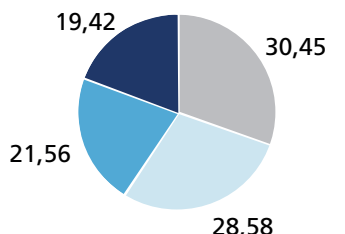

Bens de capital Bens intermediários Bens de consumo Matéria-prima

Fonte: Comtrade.

Isso fica ainda mais evidente quando se avalia a distribuição setorial dos membros, não membros e da China. Países não membros da OCDE só possuem participaçáo relevante nos mercados globais de agricultura, principalmente no de exportação de vegetais (o que inclui soja, por exemplo) e no mercado de petróleo 
e derivados. Além disso, os países membros da OCDE possuem mais de $60 \%$ do mercado global de exportaçóes em 8 dos 16 setores apresentados no gráfico 4, sempre com grande destaque para produtos de maior valor agregado.

GRÁFICO 4

OCDE: distribuição setorial das exportações por grupo de países

(Em \% do total de cada setor)

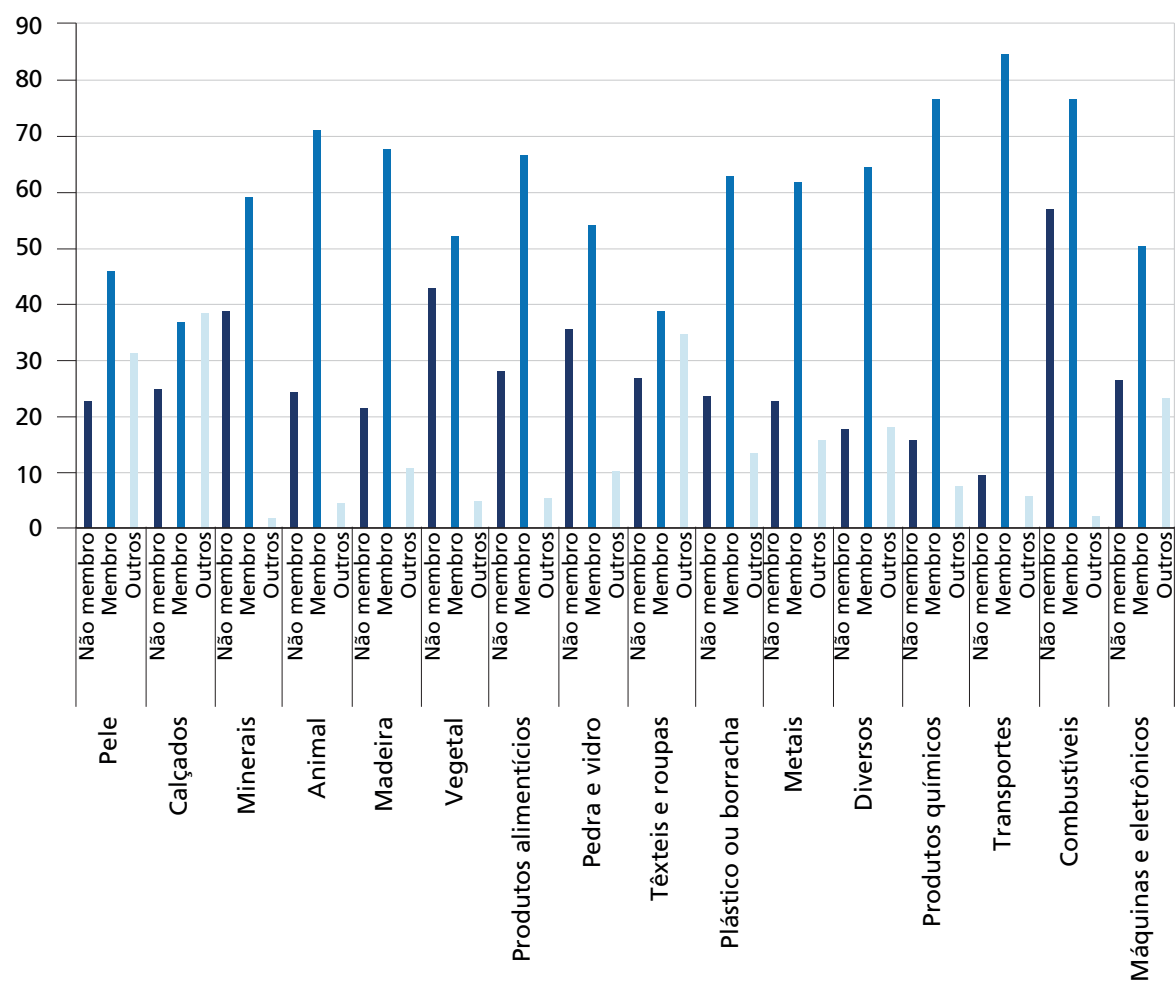

Fonte: Comtrade.

Já com relação às importaçôes (gráfico 5), é possível observar a liderança de membros da OCDE em todos os estágios de processamento da produção. Como esperado, países do grupo importam mais matéria-prima, justamente para processar, assim como também importam mais bens intermediários e de capital, o que está, em geral, associado a uma participação maior nas cadeias globais de valor (CGVs). 
GRÁFICO 5

OCDE: importações por etapa de processamento (Em \%)
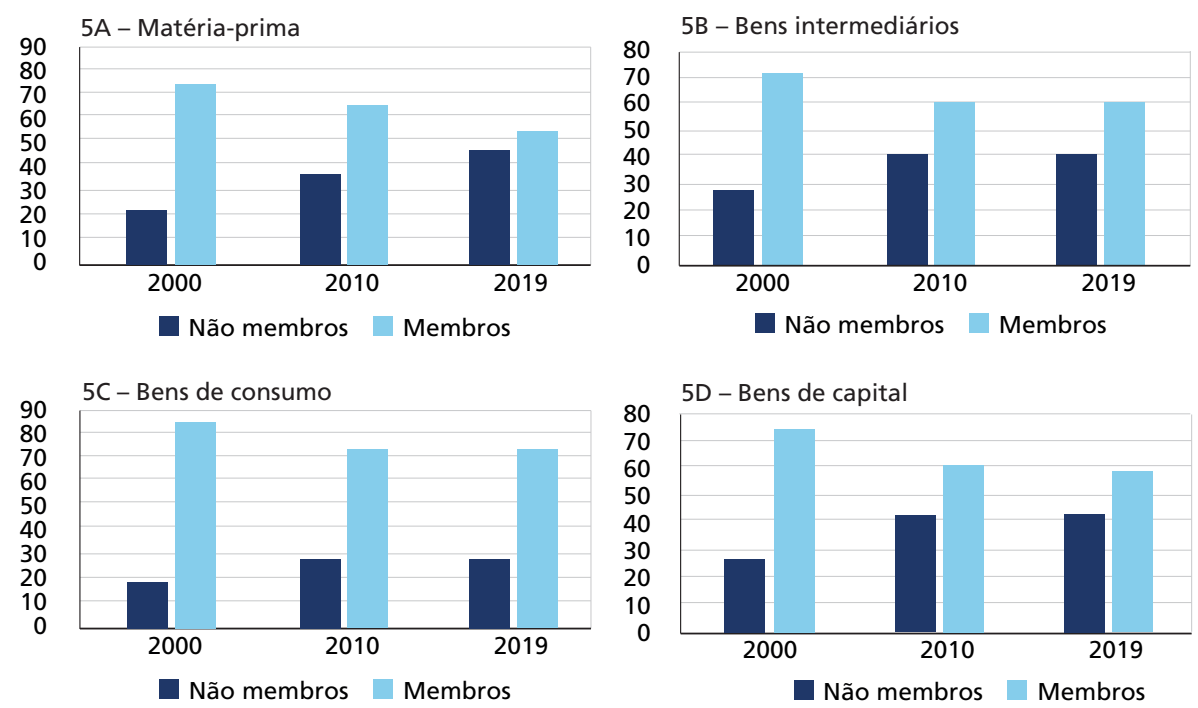

Fonte: Comtrade.

A principal razão para que as importaçóes de países membros da OCDE sejam tão maiores que as dos países não membros consiste no fato de que as tarifas para importação nos países membros da OCDE são substancialmente menores que as dos países não membros. Por exemplo, a tarifa média ponderada pelo volume de importaçóes de países membros é de $1,4 \%$, enquanto para países não membros é de $6,3 \%$.

$\mathrm{O}$ mesmo ocorre com relação à distribuição da tarifa média ponderada pelo volume de importaçóes de acordo com o estágio de processamento do produto (gráfico 6). Por exemplo, a tarifa para bens de capital e bens de consumo de países membros é 7 e 3 vezes maior que a tarifa em países não membros, respectivamente. Também se observa que a escalada tarifaria, apesar de existir para ambos os grupos, é mais significativa no caso dos países não membros. Por exemplo, o gap tarifário entre bem de consumo e matéria prima para países membros é de 1,84 p.p., enquanto para países não membros é de 2,27 p.p. O mesmo ocorre para bens de consumo e bens intermediários, que são vitais para maior integração de países não membros da OCDE nas cadeias de processamento globais.

Desse modo, fica claro que, apesar de não ser um requisito para ingressar na OCDE, adotar medidas para simplificar a estrutura tarifária e reduzir as tarifas médias é, de fato, a medida de política mais relevante que pode ser tomada por países que se interessam em entrar no grupo. 
GRÁFICO 6

OCDE: tarifa média ponderada pelo volume de importações

(Em \%)

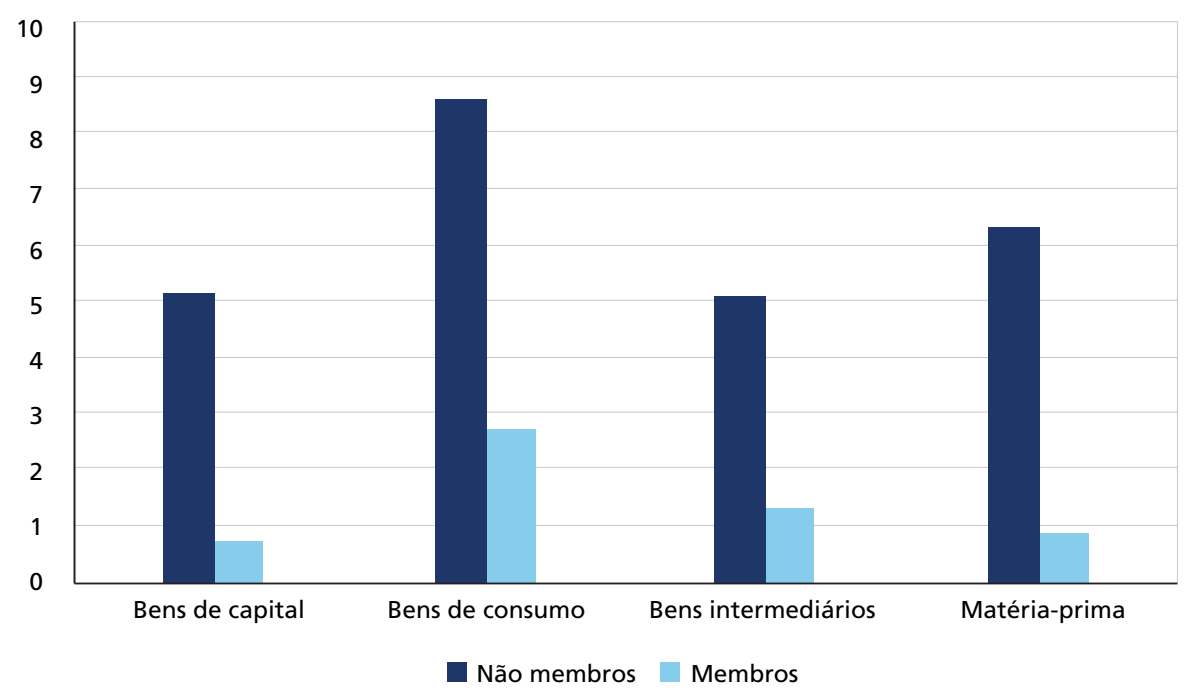

Fonte: Comtrade; Sistema de Informação de Análise Comercial (Trade Analysis and Information System - TRAINS).

Com relação ao perfil das importaçóes de países membros e não membros, também se deve considerar o papel de relevância da China nesse cálculo. Como foi feito na análise sobre o perfil de exportaçóes, apresenta-se abaixo um painel desagregando a China como parte dos países não membros.

O comportamento das importaçóes deixa claro que não há sequer um setor do mercado global em que países não membros da OCDE liderem (gráfico 7). Como era de esperar, isso é resultado do fato de os não membros possuírem tarifas muito mais elevadas que aquelas dos países membros. Além disso, pode-se observar que, em onze dos dezesseis setores apresentados, países membros da OCDE possuem mais de $60 \%$ do mercado global. No mercado de minerais, por sua vez, a China desponta como a maior importadora do mundo, à frente de ambos os grupos de países. 
GRÁFICO 7

OCDE: distribuição setorial das importações por grupo de países

(Em \% do total de cada setor)

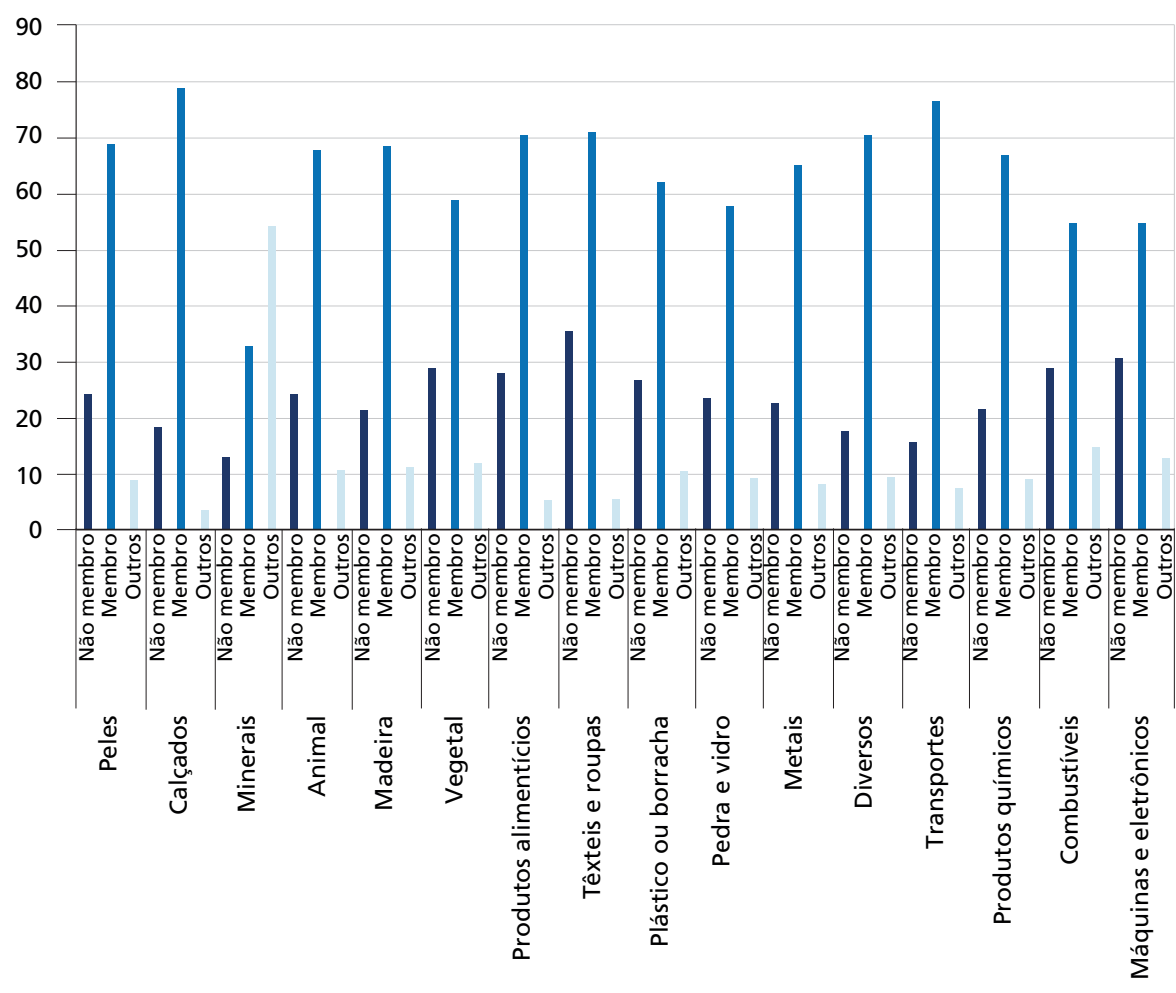

Fonte: Comtrade.

\section{INVESTIMENTOS DIRETOS, EXPORTAÇÕES E CGVs}

A partir da avaliação do perfil de comércio exterior apresentado anteriormente, valeria a pena analisar o comportamento do ingresso de IED nos países membros e como isso se relaciona com a discussão das CGVs. Dessa forma, esta seção busca avaliar a interseção entre esses dois temas e apresentar uma discussão mais profunda sobre o papel das exportaçóes e das CGVs.

Em tese, um dos impactos mais significativos para países em desenvolvimento é o reconhecimento internacional que vem com a adesão à OCDE, o que aumenta em particular a atratividade do país para os IEDs. Para algumas organizaçôes, essa adesão é uma das condiçôes necessárias para investir em um determinado país. De uma forma geral, a OCDE é um "selo de qualidade" que torna mais simples a decisão de investir (Volpe e Sztajerowska, 2019). Está claro, porém, que a adesão pode ser um fator importante na decisão de investimento, mas está longe de ser 
o único. Como mostram os autores, "quando o México e o Chile se tornaram membros da OCDE, o IED aumentou, mas isso também aconteceu em países como o Brasil, que não faz parte da organização".

Esse é um ponto importante para se considerar. Graças ao tamanho de seu mercado interno e, possivelmente, em menor medida, também a políticas em geral favoráveis, ${ }^{5}$ o Brasil tradicionalmente tem sido um dos maiores receptores de investimentos estrangeiros. O gráfico 8 indica que o país se destaca na América Latina e nos países emergentes como polo de atração de IED.

GRÁFICO 8

IED: ingresso líquido (2019)

(Em US\$ bilhões)

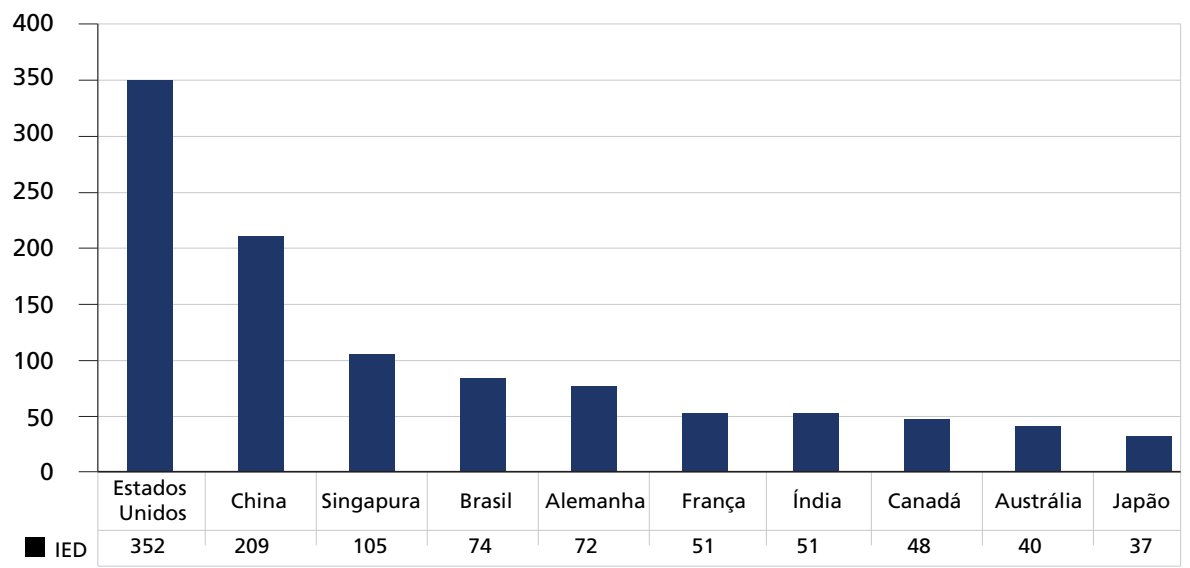

Fonte: Indicadores de Desenvolvimento do Banco Mundial (World Development Indicators - WDI).

Uma avaliação inicial do desempenho dos investimentos diretos que ocorreu nos anos logo anteriores e posteriores ao ingresso de países que ingressaram desde a década de 1990 na OCDE mostra que, para a maioria dos países que compóem a amostra, a média do crescimento do IED nos cinco anos após o ingresso na OCDE é similar a média dos cinco anos anteriores ao ingresso na organização (gráfico 9).

5. 0 Brasil tem um regime relativamente favorável à entrada de IEDs, mas preocupações históricas com escassez de divisas explicam em boa medida a presença de restrições ainda significativas. Segundo Mota Veiga e Rios (2019), "no caso do Brasil, o indicador da OCDE de restrição ao IDE situa-se pouco acima da média da OCDE e é ligeiramente inferior ao dos Estados Unidos e superior ao da Noruega. Dentre os BRICS, apenas a África do Sul tem regime de IDE mais aberto que o brasileiro, de acordo com essa metodologia. Por outro lado, dentre os países latino-americanos incluídos na amostra, o Brasil só é mais aberto que o México". 


\section{GRÁFICO 9}

OCDE: ingresso de IED - média de 5 anos antes e depois da entrada

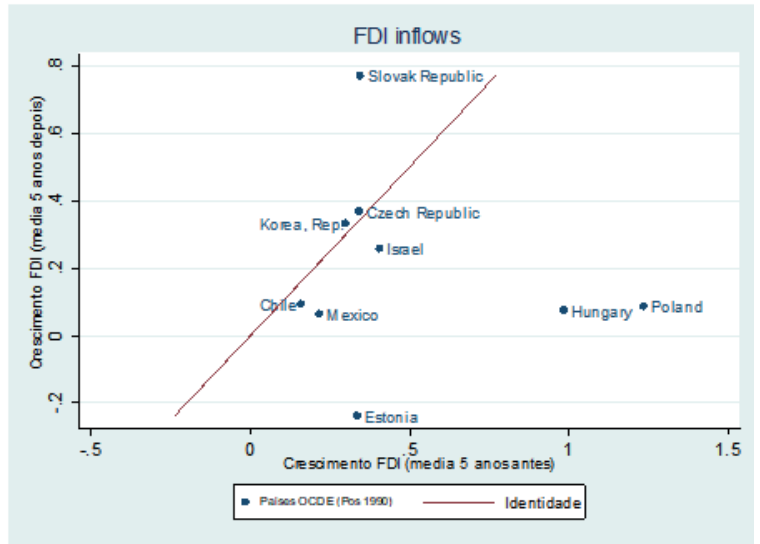

Fonte: WDI.

Obs.: Figura reproduzida em baixa resolução e cujos leiaute e textos não puderam ser padronizados e revisados em virtude das condições técnicas dos originais (nota do Editorial).

Ainda dentro da avaliação descritiva, para definir melhor que tipo de impacto esperado para o ingresso, seria interessante avaliar esse grupo de países com relaçáo a um contrafactual. Para tanto, foi criado, por meio do método de propensity score, uma paridade, de acordo com características como tamanho do produto interno bruto (PIB), tamanho da população e área geográfica, entre esse grupo de países membros e contrafactuais. $\mathrm{O}$ resultado indica que a média de crescimento do IDE, nos anos posteriores ao ingresso na OCDE, foi 0,38\% superior ao de países não membros, como se pode observar no gráfico 10.

GRÁFICO 10

OCDE: média de crescimento do IED - países membros em comparação com contrafactual

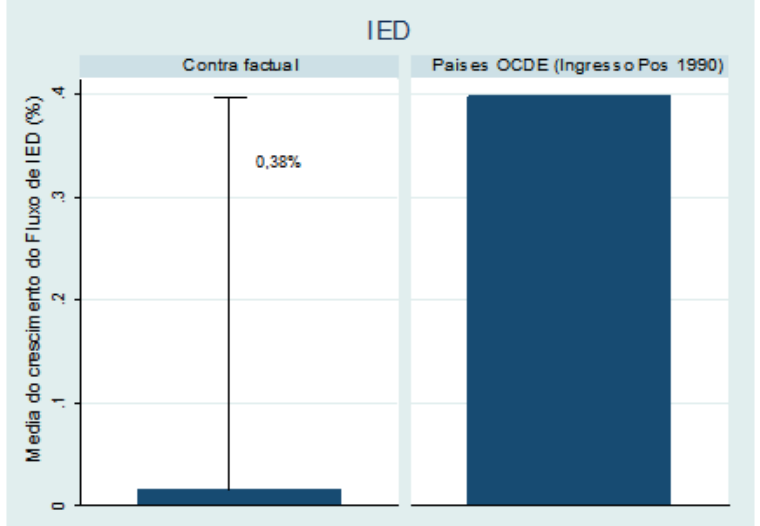

Fonte: WDI

Obs.: Figura reproduzida em baixa resolução e cujos leiaute e textos não puderam ser padronizados e revisados em virtude das condições técnicas dos originais (nota do Editorial). 
Voltando agora para o tema de comércio, o impacto esperado sobre comércio internacional é, em tese, menos direto. Ser membro da OECD não significa celebrar um acordo de livre comércio, nem impóe a redução de tarifas para o novo país membro, mudanças que tendem a gerar impactos mais imediatose profundos no comércio. Requer, sim, que o país adote boas práticas em diversas áreas que, a longo prazo, certamente contribuem para o aumento da competitividade geral e a de suas exportaçóes.

Com relação a exportaçôes e importaçôes, observa-se que, para a maioria dos países que compõem a amostra, a média do crescimento das exportações nos cinco anos após o ingresso na OCDE é similar a média dos cinco anos anteriores ao seu ingresso.

\section{GRÁFICO 11}

OCDE: crescimento do comércio exterior - média de 5 anos antes e depois da entrada $11 \mathrm{~A}$ - Exportações 11B - Importações

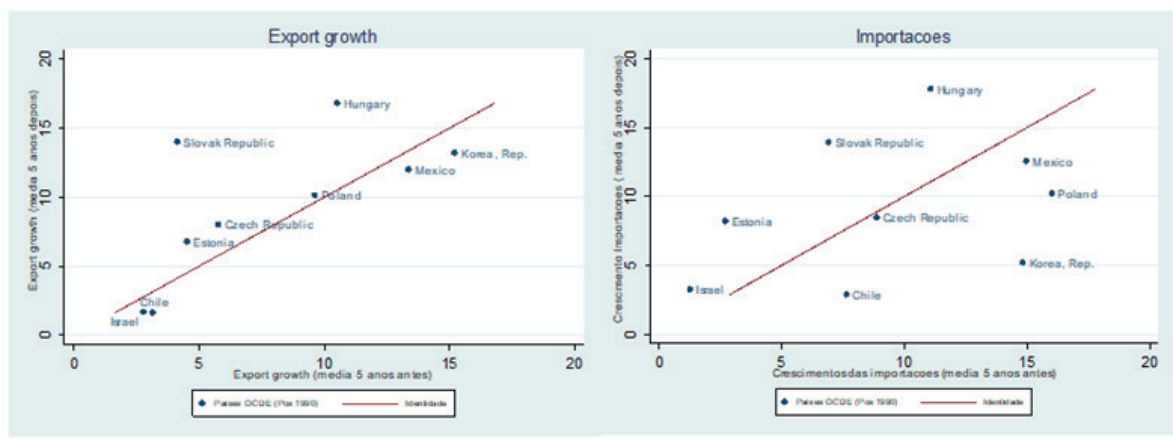

Fonte: WDI.

Obs.: Figura reproduzida em baixa resolução e cujos leiaute e textos não puderam ser padronizados e revisados em virtude das condições técnicas dos originais (nota do Editorial).

Já com relação a variação das médias em comparação com o contrafactual, pode-se perceber que os países apresentaram média de crescimento de 2,94\% superior à média do crescimento das exportaçôes do contrafactual; e 4,25\% superior à média do crescimento das importaçôes do contrafactual (gráfico 12).

O mecanismo mais direto de ampliação do comércio internacional para os participantes da OECD é por meio do comércio associado às GVCs, cuja ascensão nos últimos trinta anos é marcante. ${ }^{6}$ As GVCs existem há séculos, é verdade, mas

6. A literatura sobre desenvolvimento sugere que as GVCs, com o apoio do sistema de comércio multilateral, podem ser um impulsionador do desenvolvimento sustentável. Para os países em desenvolvimento, as GVCs geram oportunidades de participação no comércio internacional, já que, em vez de importar peças para vendas locais, eles agora podem participar de redes de produção internacionais. Por fim, as GVCs permitem o fluxo de conhecimento e tecnologia de países de alta renda para países em desenvolvimento. A literatura enfatiza ainda que a forma como os países se conectam com as GVCs determina o quanto eles se beneficiam delas. Para uma estratégia eficaz e sustentável de participação de GVC, os governos devem identificar as principais restrições vinculantes e projetar as políticas e intervenções regulatórias necessárias. Os países que adotam as políticas adequadas para mitigar os riscos associados a elas têm a oportunidade - por meio das GVCs - de aumentar o emprego e a produtividade. 
cresceram rapidamente de 1990 a 2007 à medida que os avanços tecnológicos em transporte, informação e comunicaçóes - e a redução das barreiras comerciais induziram os fabricantes a estender os processos de produção além das fronteiras nacionais. $\mathrm{O}$ crescimento das CGVs concentrou-se em máquinas, eletrônicos e transporte e nas regiôes especializadas nesses setores, especialmente Ásia e Europa (Banco Mundial, 2019). O mesmo relatório do Banco Mundial estima que o comércio de GVCs, apesar de uma desaceleração e uma pequena reversão na última década, representa cerca de 50\% do comércio internacional global.

GRÁFICO 12

OCDE: média de crescimento do comércio exterior - países membros em comparação com contrafactual

$12 \mathrm{~A}$ - Exportações 12B - Importações
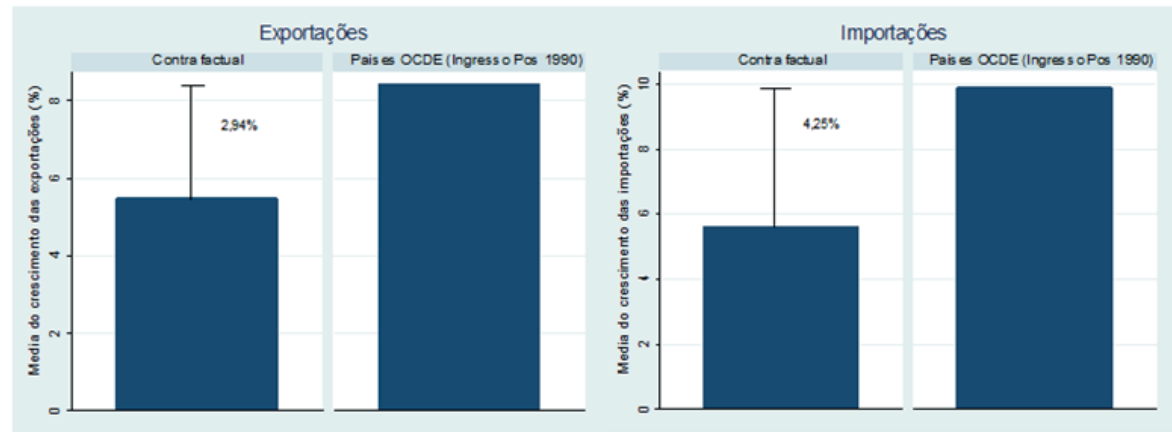

Fonte: WDI.

Obs.: Figura reproduzida em baixa resolução e cujos leiaute e textos não puderam ser padronizados e revisados em virtude das condições técnicas dos originais (nota do Editorial).

Junto com o sistema multilateral de comércio, a celebração dos chamados acordos comerciais profundos (deep trade agreements) tem sido um aspecto importante associado à expansão das GVCs. ${ }^{7}$

Acordos profundos são acordos comerciais que vão além da troca de vantagens tarifárias e incluem crescentemente dimensóes não diretamente comerciais e que definem as regras nas quais as economias operam, se integram e crescem, tais como políticas de concorrência, investimentos etc.

Por que acordos profundos são importantes? Se as cadeias globais de valor podem ser entendidas como fabricas que se estendem além das fronteiras nacionais, é claro que a separação das fases de produção através das fronteiras cria formas de transbordamentos de políticas transfronteiriças e problemas de consistência de tempo. Isso gera uma demanda por formas mais profundas de integração, ou

7. Para uma análise de como acordos profundos e produção transfronteiriça estão relacionados ver Antras e Staiger (2008) e Baldwin (2010), entre outros. 
seja, certas políticas nacionais precisam ser disciplinadas em acordos comerciais preferenciais (preferential trade agreements - PTAs) para que as GVCs operem de maneira mais eficaz.

De fato, há evidência empírica de que reformas associadas a acordos comerciais profundos têm sido um importante motor da expansão das GVCs para países participantes. Laget et al. (2018) argumentam que o aprofundamento dos acordos comerciais sustentou o surgimento das GVCs no último quarto de século, reduzindo os custos comerciais e fornecendo a infraestrutura institucional para o bom funcionamento das cadeias de valor transfronteiriças. Ruta (2017) mostra evidências de que a assinatura de acordos profundos tem um impacto grande e positivo no comércio de GVCs, entendido como o comércio de partes e componentes.

Os resultados dessa literatura mais recente sugerem que a profundidade dos acordos comerciais aumenta o comércio relacionado às GVCs entre os países participantes. O impacto, no entanto, varia de acordo com o grupo de renda. As disposiçôes extra Organização Mundial do Comércio (OMC), como política de concorrência e de investimentos, são os principais impulsionadores dessa relação, especialmente para os PTAs assinados entre países mais avançados e os PTAs Norte-Sul. As disposiçóes de fronteira ainda são um importante motor do comércio de GVC para os PTAs Sul-Sul.

Os acordos profundos estimulam os fluxos de IDE, e a relação positiva entre a profundidade de um acordo e os fluxos de IED é impulsionada principalmente por disciplinas que estáo fora do mandato da OMC (cláusulas extras da OMC). Dentro do setor manufatureiro, acordos profundos importam tanto para setores com alta ou baixa intensidade tecnológica. Os acordos profundos mitigam os custos da distância cultural.

$\mathrm{O}$ ponto aqui é que a adesão a $\mathrm{OECD}$ tem características semelhantes à dimensão não comercial de assinar um acordo profundo. É bem verdade que as normas adotadas não geram compromissos vinculantes, mas é certo que definem princípios de melhores práticas e modelos normativos cuja adoção é recomendada e cuja implementação é acompanhada por meio de mecanismos como revisão pelos pares (peer review) e pressão pelos pares (peer pressure). ${ }^{8}$

Toda essa discussão sugere um otimismo cauteloso quanto às expectativas de impactos sobre comércio da adesão à $\mathrm{OECD}$ por países de renda média como o Brasil. Primeiro, o país tem uma participação limitada em CGVs (gráfico 13). Aspectos geográficos e ligados a uma estrutura de produção e exportaçóes com forte participação de produtos agrícolas e primário explicam boa parte dessa relativa baixa

8. Vale destacar que uma confirmação dessa característica é dada pela constatação de que a OCDE não tem órgão de solução de controvérsias. 
participação (Reis et al., 2018; Hollweg e Rocha, 2018). Mais importante, todavia, é que o país segue sendo uma economia relativamente fechada, com baixa integração comercial. $\mathrm{O}$ arcabouço de política que permite aos países em desenvolvimento maximizar os ganhos da integração das GVCs é aquela em que uma "abordagem de toda a cadeia de suprimentos" deve ser adotada. Isso reflete o fato de que, em uma economia mundial na qual as GVCs desempenham um papel dominante, as importaçóes são tão importantes quanto as exportações, e os fluxos de bens, serviços, pessoas, ideias e capital são interdependentes e devem ser avaliados em conjunto.

GRÁFICO 13

CGVs: participação por país em setores selecionados (2009)

(Em \%)

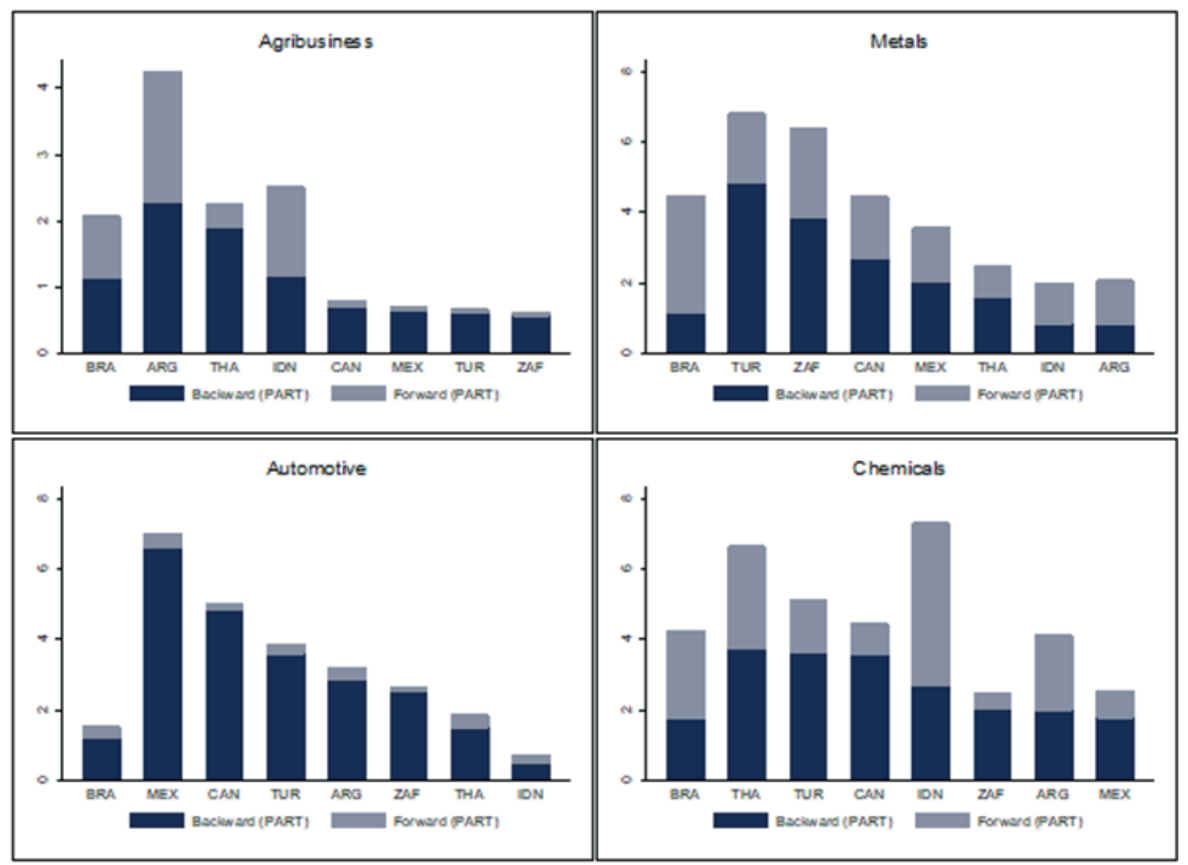

Fonte: Hollweg e Rocha (2018).

Obs.: Figura reproduzida em baixa resolução e cujos leiaute e textos não puderam ser padronizados e revisados em virtude das condições técnicas dos originais (nota do Editorial).

Nesse sentido, o impacto positivo do processo de adesáo à OCDE seria potencializado se o país concomitantemente adotasse medidas de redução de barreiras tarifarias e não tarifarias. Avanços importantes ocorreram recentemente, com a celebração do acordo (profundo) Mercado Comum do Sul-União Europeia (Mercosul-UE) e Mercosul-Shengen. Seria desejável, contudo, adotar mais medidas de liberalizaçáo, de maneira geral, mas em particular na área de tarifas de importação de bens de capital e insumos intermediários (Bauman, 2016). 


\section{GRÁFICO 14}

Equivalente tarifário da média de tarifas de importação e medidas não tarifárias Brasil e países selecionados (2015) (Em \%)

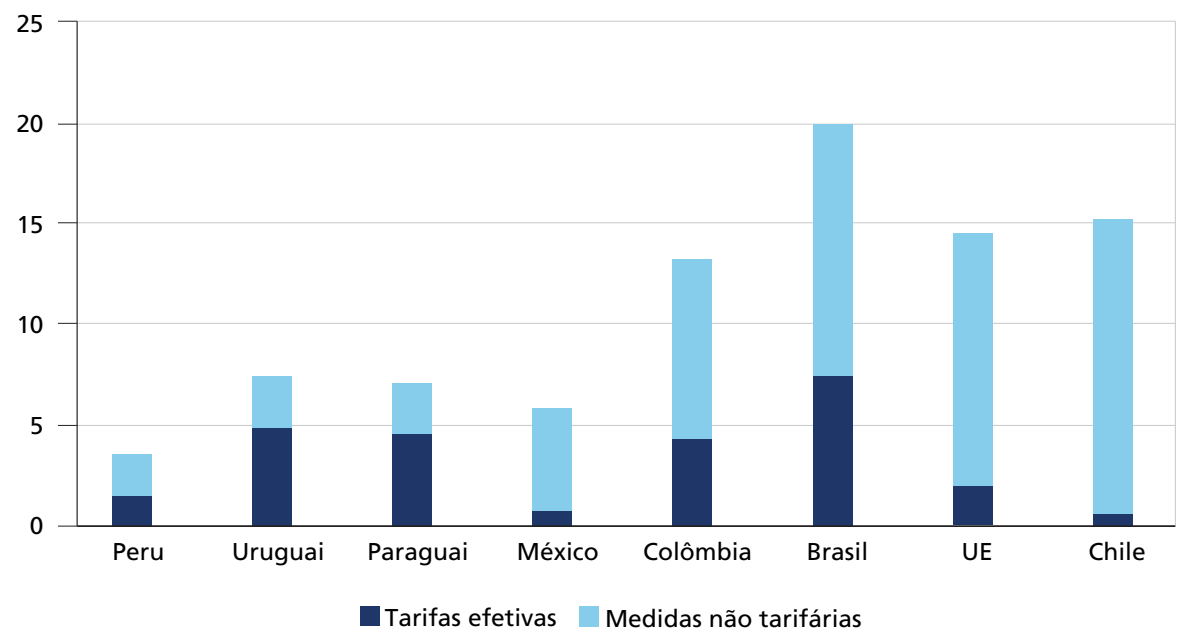

Fonte: Reis et al. (2018).

\section{RESULTADOS EMPÍRICOS}

Nesta seção, apresentamos a metodologia e base de dados utilizada, seguida dos principais resultados empíricos obtidos. Apesar da adoção das técnicas econométricas relativamente sofisticadas, não temos a pretensão de sugerir causalidade entre as variáveis analisadas, preferindo indicar que se trata de uma associação empírica que pode ser importante para avaliar futuramente os impactos do processo de adesão à $\mathrm{OCDE}$.

\subsection{Metodologia e bases de dados}

A OCDE possui 34 países membros dentre os quais 24 ingressaram no momento de sua criação (em 1961) ou nos anos imediatamente posteriores. Para conduzir esta análise exploratória, nos concentramos no grupo de países de ingresso mais recente. Apenas 10 países ingressaram a partir da década de 1990. São eles: México, República Tcheca, Polônia, Coreia do Sul, Hungria, Israel, Estônia, Chile, Letônia e Eslovênia. Para a construção do contrafactual foram usados dados de 217 países, considerando um período de cinquenta anos. Isso resultou em uma base com um pouco mais de um milhão de observaçóes.

Uma vez montada a base de dados, primeiramente procurou-se realizar análises descritivas com vistas a identificar algum tipo de tendência nos dados. 
Comparou-se a variação dos indicadores econômicos nos cinco anos anteriores e posteriores ao ingresso na OCDE.

Posteriormente, adotamos a estratégia de realizar uma regressão por meio do método de diferenças em diferenças, a fim de mensurar algum impacto do ingresso na OCDE. Para tanto, inicialmente, construiu-se um grupo de controle a partir de uma regressão logística que contou com parâmetros como PIB, população e área geográfica e coeficiente de Gini, com o objetivo de estimar a probabilidade de um país, em dado ano, ser um contrafactual para o país que ingressou na OCDE. Em seguida, foi feito um match com o emprego do método de propensity score matching (sem replacement), a fim de conectar as observaçóes e construir um contrafactual que servisse como base para a regressão.?

Antes de implementar o método de diferenças em diferenças foi realizado um balanço descritivo de como a média de cada indicador variou de acordo com o grupo de tratamento (países que ingressaram na OCDE) e controle (contrafactual construído por meio do método de propensity score).

Também foram realizadas regressóes lineares para mensurar o efeito do ingresso na OCDE nos indicadores econômicos selecionados. As regressóes consideraram erro de desvio padrão robusto (standard robust), também foram feitas regressóes com controles de efeitos fixos para país e ano.

Por fim, um modelo gravitacional para comércio exterior ${ }^{10}$ foi estimado para avaliar, especificamente, o impacto do ingresso da OCDE no comércio dos países membros e não membros. Para tanto, foi utilizado o método de Poisson pseudo-maximum-likelihood (PPML) com high dimensional fixed effects ${ }^{11}$ para controlar não somente pelos efeitos fixos de países de origem e destino e do ano, como também da interação entre eles.

A fim de obter maior nível de acurácia na estimação da associação entre ingresso na OCDE e as variáveis econômicas discutidas nesse texto, foram adotadas duas estratégias econométricas. Uma delas é a utilização do método de diferenças em diferenças para avaliar o impacto em países que ingressaram no grupo. Para isso, foi utilizada a mesma técnica de construção do contrafactual a partir da utilização de propensity score matches para definir o par país/ano de comparação.

Ademais, também se utilizou um modelo gravitacional para avaliar o impacto em termos de comércio exterior. Em ambas as estratégias de estimação, também se utilizou de efeitos fixos para avaliar o resultado.

9. Para mais detalhes sobre o método de propensity score matching, ver Austin (2011).

10. Para mais detalhes sobre o modelo gravitacional para comércio exterior, ver Silva e Tenreyro (2006).

11. Sobre a variação do modelo gravitacional que utiliza de high-dimensional variables para regressão, consultar: Larch et al. (2017). 
Os resultados indicam uma associação positiva, ainda que pequena, entre o ingresso na OCDE e o desempenho do comércio exterior. No método de PPML com efeitos fixos, chegamos a um resultado de $1,1 \%$ de aumento dos fluxos de comércio exterior para os países que ingressaram, em relação aos que não ingressaram. Isso já era esperado, como comentado na análise descritiva anterior, quando afirmamos que o ingresso na OCDE não implica compromisso por parte de governos para realizar profundas reformas em seu arcabouço de política comercial.

Por seu turno, também como esperado, utilizando diferenças em diferenças, encontramos um resultado mais robusto, 2,5\% para crescimento do IDE para países que ingressaram na $\mathrm{OCDE}$, em comparação com os países que não o fizeram. Esse parece ser o canal mais imediato pelo qual opera o selo de qualidade associado ao ingresso na organização e a realização das reformas necessárias, utilizando melhores práticas de políticas oferecidas pelo grupo. ${ }^{12}$

\section{TABELA 1}

\section{Resultado das regressões}

\begin{tabular}{|c|c|c|c|c|c|c|}
\hline Method & PPML FE & $\begin{array}{c}\text { (2) } \\
\text { PPML high dimension FE }\end{array}$ & $\begin{array}{c}\text { (3) } \\
\text { Diff in diff }\end{array}$ & $\begin{array}{c}\text { (4) } \\
\text { Diff in diff FE }\end{array}$ & $\begin{array}{c}\text { (5) } \\
\text { Diff in diff }\end{array}$ & $\begin{array}{c}\text { (6) } \\
\text { Diff in diff FE }\end{array}$ \\
\hline Variables & Import & Import & PIB & PIB & FDI & FDI \\
\hline Diff (OECD) In GPD_O & $\begin{array}{l}650,1^{3} \\
(25,20)\end{array}$ & & $\begin{array}{c}2,19^{3} \\
(0,2823)\end{array}$ & $\begin{array}{c}0,20^{1} \\
(0,0773)\end{array}$ & $\begin{array}{c}2,51^{3} \\
(0,2348)\end{array}$ & $\begin{array}{c}0,43 \\
(0,2348)\end{array}$ \\
\hline In GPD_D & $\begin{array}{l}605,3^{3} \\
(25,95)\end{array}$ & & & & & \\
\hline In Pop_O & $\begin{array}{c}3.549 \\
(63,76)\end{array}$ & & & & & \\
\hline In Pop_d & $\begin{array}{l}-234,2^{3} \\
(70,01)\end{array}$ & & & & & \\
\hline In DIST & $\begin{array}{c}-0,949^{3} \\
(0,00641)\end{array}$ & & & & & \\
\hline OECD & $\begin{array}{l}0,0880^{2} \\
(0,0354)\end{array}$ & $\begin{array}{c}-0,041 \\
(0,0251)\end{array}$ & & & & \\
\hline Constant & $\begin{array}{l}-19,52^{3} \\
(0,921)\end{array}$ & $\begin{array}{c}9,58^{3} \\
(0,173)\end{array}$ & $\begin{array}{c}27,48^{3} \\
(0,1461)\end{array}$ & $\begin{array}{c}22,80^{3} \\
(0,1929)\end{array}$ & $\begin{array}{c}23,84^{3} \\
(0,2497)\end{array}$ & $\begin{array}{c}22,91^{3} \\
(0,1846)\end{array}$ \\
\hline Observations & 1.042 .289 & 697.112 & 140 & 140 & 140 & 140 \\
\hline R-squared & 0,844 & 0,991 & 0,597 & 0,996 & 0,487 & 0,929 \\
\hline
\end{tabular}

Elaboração dos autores.

Notas: ${ }^{1} p<0.1$.

${ }^{2} p<0.05$.

${ }^{3} p<0.01$.

Obs.: Robust Standard.

12. A abundância de cautela foi utilizada como princípio para rodar as regressões pelo método de diferenças em diferença com efeitos fixos. Apesar de ser pouco provável, existe a hipótese de que outra política pode ter sido adotada por todos os países observados ao mesmo tempo que não o ingresso na OCDE. Isso justificaria também utilizar esse método. 


\section{CONCLUSÃO}

Desde o início do processo de enlargement, a adesão à OCDE tem sido um objetivo de muitos países de renda média. Desde 2016, o governo brasileiro fez da adesão à organização um objetivo explícito de política, tendo solicitado, ainda em 2017, antes mesmo de ter tido seu pleito para iniciar negociaçóes de acesso aceito, adesão aos dois códigos de liberalização da instituição. Três anos depois, o país encontra-se já em processo adiantado de convergência.

Dado que a produção normativa da OCDE não gera compromissos vinculantes, os impactos econômicos associados à adesão são predominantemente indiretos, mediante uma percepção mais favorável quanto ao clima empresarial do país que aderiu. Como citado por Mello (2020, tradução nossa),

de acordo com o governo brasileiro, assim como outros membros em potencial, a principal vantagem em ingressar na OCDE consiste em promover um ambiente de negócios melhorado, a fim de ter um impacto positivo na percepção dos investidores, o que deve resultar em níveis mais elevados de investimento. ${ }^{13}$

Usando o arcabouço teórico de CGVs, pode-se esperar também um incremento de exportaçóes resultante da adesão do país a um conjunto de regras que potencialmente o tornam um receptor mais adequado para elos da cadeia de produção. Naturalmente, a participação em CGVs depende de outras variáveis e políticas, em particular um mínimo grau de liberalização de comércio, dado o evidente caminho de duas mãos requerido para tal participação.

Neste texto, buscamos identificar padróes de comportamento de algumas variáveis econômicas em países que aderiram a OCDE pós-1990, usando diversas técnicas econométricas. Concentramo-nos em investimentos e exportaçôes, em vista do disposto. Dado o alto grau de endogeneidade e agregação envolvidos, preferimos dizer que são padróes associados ou correlacionados com o processo de adesão, mais do que uma identificação de causalidade.

Os resultados revelam correlação positiva, mas relativamente modesta, entre a adesão à organização e o crescimento de IEDs e exportaçóes. Como esperado, os efeitos parecem ser mais robustos sobre investimentos. Na nossa amostra, identificamos uma expansão de 2,5\% nos IEDs dos países que acederam à OCDE, em comparação com países que não acederam. A relação mais modesta com o desempenho das exportaçôes parece lógico, dado o mecanismo de transmissão mais indireto sobre as mesmas. De todo modo, porém, os resultados parecem confirmar outros estudos empíricos que apontam que, não obstante seus efeitos positivos, impactos mais expressivos sobre investimentos e exportaçôes vão depender de políticas mais efetivas de integração

13. "According to the Brazilian government, as well as other prospective members, the main advantage in acceding to the OECD consists in promoting an improved business environment in order to have a positive impact on investors' perceptions, which should result in higher levels of investment". 
por parte dos novos países membros. Esse certamente deve ser o caso da economia brasileira, a qual, apesar dos progressos recentes, ainda mostra um limitado grau de integração econômica e comercial com o resto do mundo.

Este artigo teve como propósito uma abordagem exploratória sobre esse tema, o qual certamente merece maior detalhamento no futuro. Nesse sentido, vale a pena sugerir algumas linhas de pesquisa que poderiam aprofundar a análise aqui apresentada. São elas:

1) Desdobrar o modelo gravitacional para avaliar o impacto em diferentes setores da economia e diferentes graus de processamento de produtos.

2) Utilizar dados com maior nível de frequência para avaliar, pelo método de diferenças em diferenças, o impacto do ingresso da OCDE. Por exemplo, utilizar de dados trimestrais de PIB.

3) Utilizar outras variáveis independentes para buscar explicar outros impactos na economia (indicadores de governança, barreiras não tarifárias, entre outros).

\section{REFERÊNCIAS}

ANTRAS, P.; STAIGER, R. Offshoring and the Role of Trade Agreements. American Economic Review, 2012, p. 102-107.

AUSTIN, P. C. An introduction to propensity score methods for reducing the effects of confounding in observational studies. Multivariate Behavioral Research, v. 46, n. 3, p. 399-424, 2011.

BALDWIN, R. E. Global supply chains: why they emerged, why they matter, and where they are going. London: CEPR, 2012. (Discussion Paper, n. 9103).

BAUMANN, R. As economias emergentes e o cenário internacional. Brasília: Ipea, 2016. (Texto para Discussão n. 2235).

CNI - CONFEDERAÇÃO NACIONAL DA INDÚSTRIA. O Brasil e os códigos de liberalizaçáo da OCDE: desafios e implicaçóes para o setor privado brasileiro. Brasília: CNI, 2020. Disponível em: <https://static.portaldaindustria. com.br/media/filer_public/3a/58/3a582315-0dd7-4b47-9af4-91ba355ccf98/o_ brasil_e_o_codigos_de_liberalizacao.pdf>.

HOLLWEG, C.; ROCHA, N. GVC Participation and deep integration in Brazil. Policy Research Working Paper, n. 8646. Washington, D. C.: World Bank Group, 2018.

LAGET, E. et al. Deep trade agreements and global value chains. Policy Research Working Paper, n. 8491. Washington, D. C.: World Bank Group, 2018. 
LARCH, M. et al. The currency union effect: a PPML re-assessment with high-dimensional fixed effects. Philadelphia: Drexel University Press, Apr. 2017. (Working Paper, n. 7).

MELLO, F. C. The OECD enlargement in Latin America and the Brazilian candidacy. Revista Brasileira de Política Internacional, Brasília, v. 63, n. 2, Oct. 2020.

REIS, J. G. et al. (2018) Trade liberalization and integration of domestic output markets in Brazil. Policy Research Working Paper, n. 8600. Washington, D. C.: World Bank Group, 2018.

RUTA, M. Preferential trade agreements and global value chains: theory, evidence, and open questions. In: WORLD BANK GROUP; IDE-JETRO; OECD; UIBE; WORLD TRADE ORGANIZATION. Global value chain development report 2017: measuring and analyzing the impact of gvcs on economic development. Washington, DC: World Bank Group, 2017.

SILVA, J. M. C. S.; TENREYRO, S. The log of gravity. The Review of Economics Statistics, v. 88, p. 641-658, 2006.

VOLPE, C.; SZTAJEROWSKA, M. Cómo armar el rompecabezas de la promoción de inversiones: un mapeo de las agencias de promoción de inversiones en América Latina y el Caribe y en los países de la OCDE. Washington, D. C.: OCDE; BID, 2019.

WORLD BANK. World Development Report 2020: trading for development in the age of global value chains. Washington, D. C.: World Bank Group, 2019.

\section{BIBLIOGRAFIA COMPLEMENTAR}

BALDWIN, R. E.; VENABLES A. J. Spiders and snakes: offshoring and agglomeration in the global economy. Journal of International Economics, v. 90, n. 2 , p. $245-254,2013$. 
